\title{
Copulatory behavior of white-footed mice (Peromyscus leucopus) in a multimale situation
}

\author{
DONALD A. DEWSBURY \\ University of Florida, Gainesville, Florida 32611
}

\begin{abstract}
Twenty male white-footed mice, Peromyscus leucopus, were tested for copulatory behavior under conditions in which either a single male or two males mated with a single female. Males did not fight over females. Qualitative aspects of copulatory behavior were unaltered in the two-male condition. There was some evidence of a social facilitation of copulatory behavior as the second ejaculations of two-male tests were attained with significantly fewer mounts and shorter inter-intromission intervals than in the one-male condition.
\end{abstract}

This study was designed to permit comparison of the copulatory behavior of white-footed mice (Peromyscus leucopus) in a multimale testing situation with that in a one-male condition. In most laboratory studies of copulatory behavior, only a single pair of animals is tested in a single arena at any given time. Such a procedure minimizes sources of interference with the unfolding of the organized copulatory pattern in its purest form. However, it is unlikely that many rodents often copulate in such controlled isolation under natural conditions. In both brown rats and black rats, for example, females mating under natural and seminatural conditions have been reported to be pursued and mounted by more than one male (Calhoun, 1962; Telle, 1966). If data on laboratory observations are to be related to behavior in the natural habitat, effects on the copulatory sequence of complicating variables, such as the presence of more than one male, must be considered.

The present study was focused about two questions. The first concerned the nature of the social interactions between the two males mating with a single female. Fighting over females and harassment of copulating pairs have been reported in a number of primate species (DeVore, 1965; Gouzoules, 1974; Jay, 1965). In other observations, primarily on rats, little fighting or harassment has been reported and agility appears to be the primary prerequisite for successful mating in the presence of other males (Barnett, 1958; Telle, 1966).

The second set of questions concerned effects of the multimale condition on the nature of the copulatory pattern itself. Should substantial qualitative changes in copulatory behavior appear, the validity for certain purposes of studies in simple social situations would be destroyed. Should somewhat smaller, quantitative effects be observed, they would also be of interest, as relatively small alterations in copulatory behavior can be of utmost importance to successful pregnancy (e.g.,

Supported by Grant BMS75-08658 from the National Science Foundation. I thank the Schering Corporation for providing estradiol benzoate and progesterone, and Dr. J. A. King for providing stock of Peromyscus leucopus.
Adler, 1969). An example of a quantitative change in copulatory behavior in a more complex social situation was provided by Larsson (1956), who reported a facilitation of certain aspects of the copulatory behavior of laboratory rats tested in groups of three males and three females in a single cage.

The subjects in the present research were whitefooted mice, Peromyscus leucopus. Whereas Norway rats are a "contact" species living in groups (e.g., Telle, 1966), male $P$. leucopus appears to occupy nonoverlapping home ranges during the breeding season (Metzgar, 1971). One might expect a higher level of aggressive interaction from species such as white-footed mice, which lack the tolerance of spatial proximity which characterizes Norway rats.

\section{METHOD}

The subjects for this study were 20 male and 13 female white-footed mice, Peromyscus leucopus from the colony maintained at the University of Florida (Dewsbury, 1975). These mice were selected from an original pool of 57 males and 54 females on the basis of their having copulated to ejaculation in at least one pretest. All were at least 90 days of age.

Males were housed in plastic cages, $48 \times 27 \times 13 \mathrm{~cm}$, while females were housed in plastic cages measuring $29 \times 19 \times 13 \mathrm{~cm}$. Litter material (San-i-cel), bedding (Nestlets-Ancare Corp.), water, and Purina Lab Chow were provided. The mice were tested in the colony room, which was maintained on a reversed 16:8 photoperiod with white light coming on at $0930 \mathrm{~h}$. Dim red light shone at all times.

Each male received one test in each of two conditions: the one-male and two-male conditions. Tests were separated by at least 2 weeks. Half of the males received their tests in each possible running order. Tests in the one-male condition were initiated with the introduction of a female into the male's home cage. Males were permitted a minimum of $90 \mathrm{~min}$ to initiate copulation. If copulation occurred, tests were permitted to continue until attainment of a satiety criterion of $30 \mathrm{~min}$ with no copulations or until 5:30 p.m. when the lights went on. Three days prior to testing in the two-male condition, two males were placed in a cage identical to their home cages, but which had not served as the home cage for either. Tests were conducted using procedures identical to those of the one male condition, except for the presence of two males.

Females were brought into behavioral estrus with sequential injections of $0.06 \mathrm{mg}$ estradiol benzoate 3 days before testing and $0.6 \mathrm{mg}$ progesterone approximately $6 \mathrm{~h}$ before testing. 
Copulatory behavior in white-footed mice is comprised of "Series" of mounts (without vaginal insertion), intromissions (with vaginal penetration, but no sperm transfer), and ejaculations (with both insertion and sperm transfer) (Dewsbury, 1975). Each series ends with an ejaculation. The following standard measures were used: Mount latency (ML), latency from the start of a test to the first mount or intromission; intromission latency (IL), latency from the start of the test to the first intromission; ejaculation latency (EL), time from the first intromission of a series to its terminal ejaculation; intromission frequency (IF), the number of intromissions in a series; mount frequency (MF), the number of mounts in a series; mean interintromission interval (MIII), the mean interval separating the intromissions of a series; post-ejaculatory interval (PEI), the period from ejaculation to the next intromission; ejaculation frequency (EF), the number of ejaculations in a test; and intromission frequency (post ejaculation) (IFPE), the number of intromissions and long intromissions occurring after the last ejaculation of a test. A hyphen and number following an abbreviation designate the series to which the measure refers (e.g., IF-2).

\section{RESULTS}

While males often appeared more "excited" in the two-male condition than in the one-male condition, no evidence of fighting was observed. The description provided by Barnett (1958) for wild rats provides an accurate portrayal of the behavior observed in the present study with white-footed mice: "The males did not fight; nor did they adopt any kind of threat posture towards each other: they occasionally sniffed each other and sometimes, as if confused or 'over-excited,' one mounted another and this led to a momentary scuffle. On no occasion was there any behavior which could be called fighting for, or over, a female" (p. 124).

Four males which mated in the one-male condition failed to copulate in the two-male condition in tests when the other male did mate and thus the female was known to be receptive. In several instances, the males pursued the females persistently but failed to achieve intromissions. There was no fighting or overt agonistic behavior between these males.

There were no qualitative differences in copulatory behavior as a function of condition. Quantitative data were analyzed for the 16 males which mated under both conditions. For each measure, analyses included data from all animals providing data under both conditions. Mean scores, standard errors, and the results of matched $t$ tests are presented in Table 1. The only significant differences as a function of condition appeared in the second series, where both MF and MIII were lower in the two-male condition.

In some instances, periods of copulatory activity appeared synchronized, so that either both or no males would be active in a given period. On other occasions, however, males were not synchronized, sometimes appearing to alternate bouts of activity.

\section{DISCUSSION}

Under present conditions, there was no evidence of fighting over females or of harrassment of copulating males in $P$.
Table 1

Measures of Copulatory Behavior in Peromyscus leucopus Tested in the One Male and Two Male Conditions

\begin{tabular}{|c|c|c|c|c|c|}
\hline \multirow[b]{2}{*}{ Measure } & \multicolumn{2}{|c|}{ One Male } & \multicolumn{2}{|c|}{ Two Male } & \multirow[b]{2}{*}{$\mathrm{t}$} \\
\hline & Mean & SE & Mean & $\mathrm{SE}$ & \\
\hline $\mathrm{ML}^{*}$ & 1211.6 & 308.2 & 988.8 & 233.8 & .62 \\
\hline $\mathrm{IL}^{*}$ & 1349.6 & 346.2 & 1136.8 & 230.0 & .55 \\
\hline EL-1* & 612.8 & 237.4 & 637.8 & 193.8 & .07 \\
\hline IF-1 & 4.8 & 1.0 & 5.2 & .8 & .36 \\
\hline MF-1 & 4.5 & 1.4 & 2.4 & .6 & 1.25 \\
\hline MIII-1 * & 141.3 & 57.9 & 98.5 & 23.5 & .62 \\
\hline PEI-1* & 570.8 & 70.8 & 524.1 & 72.9 & .39 \\
\hline EL-2* & 384.1 & 164.1 & 234.5 & 116.9 & .70 \\
\hline IF-2 & 8.7 & 2.0 & 6.2 & 1.6 & .92 \\
\hline MF-2 & 3.8 & 1.0 & 1.8 & .5 & $2.37 \dagger$ \\
\hline MIII-2* & 55.4 & 15.1 & 33.8 & 12.0 & $2.70 \dagger$ \\
\hline PEI-2* & 637.4 & 83.0 & 687.8 & 117.5 & .70 \\
\hline $\mathrm{EF}$ & 2.5 & .2 & 3.0 & .3 & .48 \\
\hline IFPE & 11.8 & 6.8 & 11.9 & 3.8 & .01 \\
\hline
\end{tabular}

leucopus. These observations are virtually identical to those of Barnett (1958) and Telle (1966) on wild rats. While rats live in relatively stable multimale groups, white-footed mice occupy home ranges which are nonoverlapping with other members of their species and sex. Thus, the similarity of social interactions during copulation in the laboratory contrasts with the differences in social interactions which appear to occur in the natural habitat.

The general invariance of qualitative aspects of copulatory behavior in the two-male situation provides further evidence for the stability of such patterns. Basic copulatory patterns appear not to vary in different natural populations (Dewsbury, 1974; Dewsbury \& Lovecky, 1974) or as a result of domestication (Estep, Lanier, \& Dewsbury, 1975). Such invariance is important in assessing the generality of results from studies conducted under restricted laboratory conditions.

Some evidence for a social facilitation of quantitative measures of copulatory behavior was found in the second series. There were fewer mounts and shorter mean inter-intromission intervals in the two-male condition than in the one-male condition. In addition, ejaculation latency was reduced in 11 males and increased in 2 , whereas intromission frequency was reduced in 8 males, increased in 3 , and unchanged in 2 males. The social facilitation of copulatory activity resembles that reported by Larsson (1956) in his comparisons of laboratory rats mating in groups of three males and three females as compared to the behavior of an isolated pair. The greater sensitivity to experimental treatment of second series behavior relative to that of the first series is a common observation in studies of copulatory behavior (e.g., Dewsbury, 1969, 1971; Jackson, 1975).

\section{REFERENCES}

AdLer, N. T. Effects of the male's copulatory behavior on successful pregnancy of the female rat. Journal of Comparative and Physiological Psychology, 1969, 69. 613-622.

BARNETT, S. A. An analysis of social behavior in wild rats. Proceedings of the Zoological Society of London, 1958, 130. 107-152.

Calmoun, J. B. The ecology and sociology of the Norway rat. Bethesda, MD: U.S. Department of Health, Education, and Welfare, 1962.

DEVore, I. Male dominance and mating behavior in baboons. In F. A. Beach (Ed.), Sex and behavior. New York: Wiley, 1965. Pp. 266-289. 
Dewsbury, D. A. Copulatory behavior of rats (Rattus norvegicus) as a function of prior copulatory experience. Animal Behaviour, 1969, 17, 217-223.

DewsBury, D. A. Copulatory behavior of male rats following reserpine administration. Psychonomic Science, 1971, 22, 177-179.

DewsBuRY, D. A. Copulatory behavior of wild-trapped and laboratory-reared cactus mice (Peromyscus eremicus) from two natural populations. Behavioral Biology, 1974, 11, 315-326.

Dewsbury, D. A. Copulatory behavior of white-footed mice (Peromyscus leucopus). Journal of Mammalogy, 1975. 56, 420-428.

Dewsbury, D. A., \& Lovecky, D. V. Copulatory behavior of old-field mice (Peromyscus polionotus) from different natural populations. Behavior Genetics, 1974, 4, 347-355.

EsteP, D. Q., LANier, D. L., \& Dewsbury, D. A. Copulatory behavior and nest building behavior of wild house mice (Mus musculus). Animal Learning \& Behavior, 1975, 3. 329-336.

Gouzoules, H. Harassment of sexual behavior in the stumptail macaque, Macaca arctoides. Folia Primatologica, 1974, 22. 208-217.
JACKSON, S. K. Recovery from sexual satiety in male rats. Doctoral dissertation, University of Florida, 1975.

JAY, P. The common langur of north India. In I. DeVore (Ed.), Primate behavior. New York: Holt, Rinehart, \& Winston, 1965. Pp. 197-249.

LARSSON, K. Conditioning and sexual behavior in the male albino rat. Stockholm: Almqvist \& Wiksell, 1956.

Metzgar, L. H. Behavioral population regulation in the woodmouse, Peromyscus leucopus. American Midland Naturalist, 1971, 86, 434-448.

Telle, H. J. Contribution to the knowledge of behavioural patterns in two species of rats, Rattus norvegicus and Rattus rattus. Zeitschrift fur Angewandte Zoologie, 1966, 53, 129-196 (Tr. V. N. Nekrassoff).

(Received for publication December 22, 1975.) 